\title{
Unilateral pallidotomy for Parkinson's disease: results after more than 1 year
}

\author{
A Schrag, M Samuel, E Caputo, T Scaravilli, M Troyer, C D Marsden, D G T Thomas, \\ A J Lees, D J Brooks, N P Quinn
}

\begin{abstract}
Objective-To examine follow up results of unilateral ventral medial pallidotomy in 22 patients with advanced Parkinson's disease more than 1 year after the operation in comparison with their results (previously reported) at 3 months.

Methods-Twenty patients who had undergone unilateral pallidotomy were assessed with the core assessment programme for intracerebral transplantation (CAPIT) protocol preoperatively, at 3 months postoperatively, and again after a median postoperative follow up of 14 months. Two further patients had only one evaluation 3 months postoperatively.

Results-The reduction of contralateral dyskinesias (median 67\%) at 3 months was slightly attenuated after 1 year to $55 \%$ (both $\mathbf{p}<0.001$ compared with baseline). A less pronounced effect on ipsilateral and axial dyskinesias decreased from $39 \%$ to $33 \%(p<0.005$ and $p<0.01)$, and from $50 \%$ to $12.5 \%(\mathrm{p}<0.001$ and $\mathrm{p}<0.01)$, respectively. However, there was no significant change between the 3 month and the follow up assessment. The modest improvement of the contralateral unified Parkinson's disease rating scale (UPDRS) motor score in the "off" state remained improved compared with preoperative levels, but less significantly $(26 \%, \mathrm{p}<0.001$, and $18 \%, p<0.01)$. The activities of daily living (ADL) subscore of the UPDRS in the off state remained improved with median changes of $23 \%$ and $22 \%$ at follow up (both $\mathrm{p}<0.005$ ). There was no significant improvement of "on" state or ipsilateral off state motor scores. Median modified Hoehn and Yahr scores in off and on state were unchanged, as was the time spent off. Speech in off had significantly deteriorated by 1 year after the operation. Conclusions-The beneficial effects of unilateral pallidotomy persist for at least 12 months and, dyskinesias are most responsive to this procedure.

(F Neurol Neurosurg Psychiatry 1999;67:511-517)
\end{abstract}

Keywords: Parkinson's disease; pallidotomy; treatment; adverse events

Although the introduction of levodopa revolutionised the treatment of Parkinson's disease, advanced disease is complicated by disabling motor fluctuations, levodopa induced dyskinesias, and symptoms unresponsive to dopaminergic therapy. In recent years, pallidotomy has re-emerged as an effective treatment and more than 1000 of these procedures have been performed. ${ }^{1}$ However, a limited number of formally evaluated studies have been reported and there are considerable differences in the outcomes from different centres. ${ }^{2-10}$ It is clear that the principal effect of medial globus pallidus pallidotomy is to dramatically improve contralateral treatment induced dyskinesias. ${ }^{45-10}$ Most centres also report a lesser amelioration of ipsilateral dyskinesias, ${ }^{3610}$ and of off state parkinsonism (bradykinesia, rigidity, and tremor) contralateral to the surgical lesion, ${ }^{34671011}$ percentage of time spent in off state. ${ }^{311}$ Ipsilateral parkinsonian features and axial features such as gait and freezing may also improve, ${ }^{46811}$ but "on" state parkinsonism and the preoperative dose of medication generally remain unchanged. ${ }^{6} 1012$ However, few long term follow up results of pallidotomy are available, and it is not clear whether the beneficial effects persist. Some of the short term benefit may even be attributable to a placebo effect as none of the published studies have been placebo controlled. Long term follow up data are therefore necessary to determine the persisting benefit of this procedure, particularly in view of the potential risk of side effects. ${ }^{2} 4910$

We here report clinical follow up after more than 1 year of 22 patients who underwent unilateral pallidotomy at the National Hospital for Neurology and Neurosurgery. The results of the assessment 3 months postsurgery have been reported previously. ${ }^{10}$

\section{Methods}

Twenty six consecutive patients, who fulfilled UKPDS Brain Bank criteria for idiopathic Parkinson's disease ${ }^{13}$ and were experiencing disabling dyskinesias uncontrolled by medical treatment, originally underwent unilateral stereotactic pallidotomy contralateral to the more severely affected side. Patients with dementia were excluded. The study was approved by the joint ethics committee of the National Hospital for Neurology and Neurosurgery and the Institute of Neurology. Informed consent was obtained from each patient before surgery. The surgical methods have been described previously. ${ }^{10}$ Briefly, anatomical coordinates for the lesion were planned on the basis of immediate preoperative CT with a Cosman-Roberts-Wells stereotaxic frame in place, and during the operation microelectrode recordings from the pallidum followed by high frequency stimulation with the lesioning electrode were used to further 
determine the appropriate lesion site. Pallidotomy was performed by thermocoagulation in two to four overlapping individual lesions. All patients had routine brain MRI preoperatively and also 1-2 days postoperatively. The clinical evaluations were performed 1-3 months before surgery, and then 3 months and at least 1 year after surgery. All patients were assessed according to the core assessment programme for intracerebral transplantation (CAPIT) protocol including a standardised levodopa challenge. ${ }^{14}$ All but four patients were assessed by the same rater at baseline, and 3 month and 1 year follow up. The remaining four patients were assessed both at baseline and 3 months by the same rater, but at 1 year by a second rater. The complete unified Parkinson's disease rating scale (UPDRS) scale and a dyskinesia scale ${ }^{15}$ were rated separately for each limb, neck, and trunk, and the modified Hoehn and Yahr scale was scored in the practically defined off state in the morning at least 12 hours after the last dose of levodopa, and in the best on state after a standardised dose of 200 $\mathrm{mg}$ levodopa plus $50 \mathrm{mg}$ benserazide in dispersible form. The dyskinesia rating scale was scored every 20 minutes thereafter to determine the time of the best on and the time of worst dyskinesias, as many patients had diphasic dyskinesia patterns. Additionally, timed tests of rapid alternating pronationsupination of each hand (20 times), repetitive hand-arm movements between two points 30 $\mathrm{cm}$ apart (10 times), finger dexterity (sequential finger to thumb opposition, 10 times), and of walking 7 metres from and to a sitting position as outlined in the CAPIT, were performed at these times. We endeavoured to hold constant the dose of antiparkinsonian medication for at least 1 month before the operation and throughout the follow up period unless the patient's condition dictated a change.

Pairwise statistical comparison of ordinal data from the preoperative evaluation, the follow up evaluation at 3 months, and the evaluation at more than 1 year used the Wilcoxon signed rank tests. To take into account the multiple number of comparisons performed, a statistical threshold of $\mathrm{p}<0.005$ was considered to be sufficiently conservative. Differences with $\mathrm{p}<0.05$ were considered as marginally significant. The statistical analysis was performed for the 20 patients with both a 3 month follow up and a follow up after more than 1 year assessment to enable a comparison between the evaluation at 3 months and longer follow up. As the time of follow up period ranged from 12 to 22 months, we tested the correlation of duration of follow up and changes from baseline to follow up assessment, adjusted for baseline score, but did not find any significant effect of duration of follow up on change in any variable.

Hemibody dyskinesia scores were calculated from the sum of the dyskinesia scores of arm and leg on each side of the body, and axial dyskinesia scores were determined from the sum of neck and trunk dyskinesias rated according to the scale of Goetz et al. ${ }^{15}$ Hemibody parkinsonism for each side was calculated as the sum of items 20-26, tremor from items 20-21, rigidity from item 22 , and bradykinesia from items 23-26, separately for each side. Gait and postural stability scores were calculated from the sum of items 13-15 and 27-30, speech from items 5 and 18, and dexterity from questions 9-11. Statistical comparisons of individual traits (tremor, rigidity, etc) were performed for the patients with mean preoperative UPDRS scores of 1.0 or higher in these items. The time spent off, and on with dyskinesias, was derived from the UPDRS scale $(1=0-25 \%$; $4=75-100 \%)$. Changes in medication were determined by calculating the levodopa/ decarboxylase inhibitor (DDCI) equivalent dose as described previously, ${ }^{10}$ and compared by student's $t$ tests. As there are no conversion factors for apomorphine, patients with changes in their dose of apomorphine were excluded from this analysis of drug dosages.

\section{Results}

Twenty six patients (mean age 55.9; range 40-69, and mean disease duration 15.4; range 5-25 years) underwent unilateral pallidotomy. Mean modified Hoehn and Yahr stage preoperatively was 4 (range 2-5) in off and 3 (range 2-4) in on. Twenty one patients had left sided and five had right sided pallidotomy. Postoperative MRI confirmed the lesion in the medial pallidum in all cases (for details see Samuel et $\left.a l^{10}\right)$. In one patient (the first in the series) there was extension of the lesion into the posterior limb of the internal capsule. In three other

Table 1 Median change (from preoperative baseline) of dyskinesia and UPDRS scores 3 months and more than a year postoperatively ( $n=20$ )

\begin{tabular}{|c|c|c|c|c|c|c|c|}
\hline Off state & $\begin{array}{l}3 \text { months } \\
\text { (\% change) }\end{array}$ & $\begin{array}{l}>1 \text { year } \\
(\% \text { change) }\end{array}$ & $\begin{array}{l}\text { p Value } \\
\text { (3 months-1 year) }\end{array}$ & On state & $\begin{array}{l}3 \text { months } \\
\text { (\% change) }\end{array}$ & $\begin{array}{l}>1 \text { year } \\
\text { (\% change) }\end{array}$ & $\begin{array}{l}\text { p Value } \\
\text { (3 months }-1 \text { year) }\end{array}$ \\
\hline$\overline{\mathrm{ADL}}$ & $23^{\star \star \star}$ & $21.6^{\star \star \star}$ & NS & $\mathrm{ADL}$ & 0 & 8.3 & NS \\
\hline Total motor score & $16.3 \star \star$ & $18.3^{\star \star}$ & NS & Total motor score & -2.8 & -5.6 & NS \\
\hline Contralateral motor score & $25.9^{\star \star \star \star \star}$ & $17.9^{\star \star}$ & NS & Contralateral motor score & & & NS \\
\hline Ipsilateral motor score & 8.8 & 10.6 & NS & Ipsilateral motor score & -14.6 & -25 & NS \\
\hline Contralateral bradykinesia & $17.9^{\star}$ & 13.3 & NS & & & & \\
\hline Contralateral rigidity & $25^{\star \star \star}$ & $40.2^{\star \star \star}$ & NS & On period dyskinesia & & & \\
\hline \multirow[t]{2}{*}{ Contralateral tremor } & $50^{\star}$ & $50^{\star}$ & NS & Total & $48.3^{\star \star \star \star \star}$ & $37.5^{\star \star \star \star \star}$ & NS \\
\hline & & & & Contralateral & $66.7^{\star \star \star \star \star}$ & $55^{\star \star \star \star}$ & NS \\
\hline Ipsilateral bradykinesia & 0 & -10.1 & NS & Ipsilateral & $38.8^{\star \star \star}$ & $33.3^{\star \star}$ & NS \\
\hline Ipsilateral rigidity & $22.5^{\star}$ & 31 & NS & Axial & $50^{\star \star \star \star \star}$ & $12.5^{\star \star}$ & NS \\
\hline Ipsilateral tremor & 20 & 20 & NS & & & & \\
\hline Gait & $3.9^{\star}$ & $3.6^{\star \star}$ & $<0.05$ & Gait & 16.7 & & $<0.05$ \\
\hline Speech & 0 & $-50^{\star \star \star \star}$ & $<0.005$ & Speech & 0 & $8.3^{\star}$ & $<0.01$ \\
\hline Dexterity (ADL) & $28.6^{\star}$ & $18.2^{\star \star}$ & NS & Dexterity (ADL) & 0 & 0 & NS \\
\hline
\end{tabular}

Positive values represent improvement, negative ones worsening

${ }^{\star} \mathrm{p}<0.05 ;{ }^{\star \star} \mathrm{p}<0.01 ;{ }^{\star \star \star} \mathrm{p}<0.005 ;{ }^{\star \star \star \star} \mathrm{p}<0.001$; significant change in comparison with preoperative values; $\mathrm{NS}=$ not significant; Dexterity (ADL) $=$ composite of questions $9-11$ of ADL part of UPDRS 

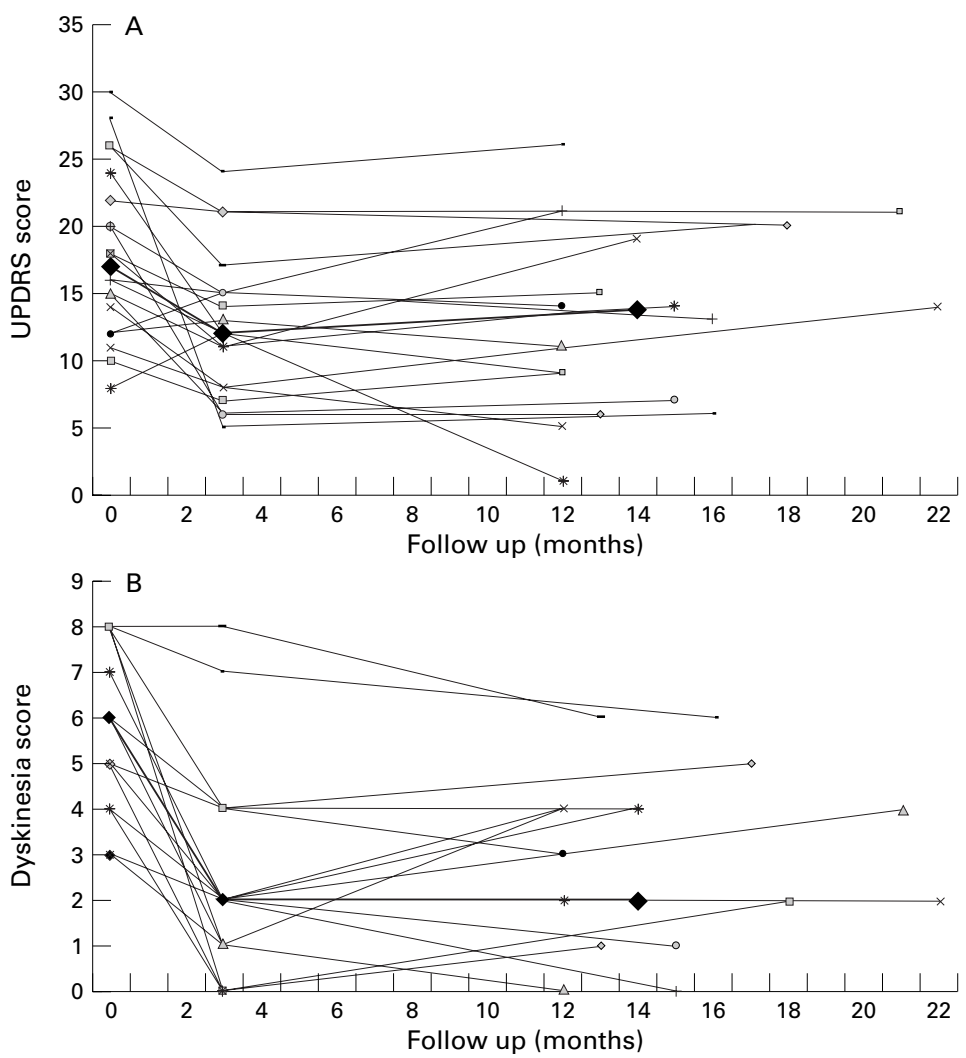

Figure 1 (A) Contralateral motor UPDRS score in practically defined off, and (B) on period dyskinesia scores of all patients with an evaluation 3 months and more than 1 year postoperatively. The bold line represents the median score.

patients among the first 10 operated on there was more dorsal and lateral extension to include a portion of lateral pallidum. Two patients had fatal complications related to the operation (see adverse events). Two patients were not available for the 3 month assessment, but both subsequently had a long term assessment. One patient died of a glioma 6 months postoperatively, and one patient could not be assessed more than 1 year postoperatively due to paranoid psychosis (see adverse events). Therefore, 22 patients were assessed at 3 months and 22 at more than 1 year after surgery (median follow up 14, range 12-22 months). Twenty patients had both postoperative assessments.

TREATMENT INDUCED DYSKINESIAS

Contralateral dyskinesias in the 20 patients assessed at both follow up times had significantly improved by $67 \%$ after 3 months $(p<0.001)$ and were still improved by $55 \%$ $(\mathrm{p}<0.001)$ compared with preoperative scores more than 1 year after surgery (table 1 and fig 1A). Ipsilateral dyskinesias, which were significantly improved after 3 months by $39 \%$ $(\mathrm{p}<0.001)$, remained so improved at the follow up assessment, albeit less significantly (change from baseline $33 \%, \mathrm{p}<0.01$ ), and axial dyskinesias, which were improved by $50 \%$ at 3 months $(\mathrm{p}<0.001)$, were only marginally improved, by $12.5 \%$, at follow up $(\mathrm{p}<0.01)$. However, there were no significant differences in any of these dyskinesia scores between evaluations at 3 months and more than 1 year. In one of the three patients with extension to lateral pallidum dyskinesias had worsened after 1 year.

UPDRS SCORES IN THE OFF STATE

The contralateral motor score, which had significantly improved by $26 \%$ after 3 months $(\mathrm{p}<0.001)$, was still improved at follow up, but less $(18 \%)$ compared with baseline $(p<0.01$, fig $1 \mathrm{~B})$. The contralateral improvement was most marked for rigidity $(25 \%$ and $40 \%$, respectively, $\mathrm{p}<0.005$ for both assessments), and tremor $(50 \%$ and $50 \%$, respectively, $\mathrm{p}<0.05$ for both assessments), and was maintained throughout the follow up period, but was only marginally significant at 3 months after surgery. There was marginally significant improvement of ipsilateral rigidity at 3 months but the total ipsilateral motor score was not improved. However, there was no deterioration of this variable after more than 1 year, as might perhaps have been expected with progression of the disease. Overall, there was moderate, marginally significant, improvement of the off state UPDRS motor score, which was maintained for more than 1 year $(16 \%$ and $18 \%$, respectively, $\mathrm{p}<0.01$ at both assessments). Dexterity, as indicated by the activities of daily living (ADL) section of the UPDRS (cutting food, hygiene, and dressing) had improved marginally after 3 months $(29 \%, p<0.05)$ and was still improved after more than 1 year $(18 \%$, $\mathrm{p}<0.01)$. Gait in off was only marginally improved, by $4 \%(\mathrm{p}<0.05)$, but this state was maintained for more than 1 year $(\mathrm{p}<0.01)$. On the other hand speech, as measured by the ADL part of the UPDRS, which was unchanged after 3 months, had deteriorated significantly a year later (dysarthria in five patients, increase in hypophonia of 1 or 2 out of 10 points in two items of the UPDRS scale in 10 patients, $\mathrm{p}<0.001)$. The overall off state ADL score was improved at 3 months $(23 \%$, $\mathrm{p}<0.005)$ and this improvement was maintained throughout the follow up period $(22 \%$, $\mathrm{p}<0.005$; table 1$)$. In one of the three patients

Table 2 Median of UPDRS subscores preoperatively and postoperatively after 3 months and more than 1 year ( $n=20)$

\begin{tabular}{lllllll}
\hline & $\begin{array}{l}\text { Preoperative } \\
\text { (range) }\end{array}$ & $\begin{array}{l}3 \text { months } \\
\text { (range) }\end{array}$ & $\begin{array}{l}\text { p Values } \\
\text { (pre-3 } \\
\text { months) }\end{array}$ & $\begin{array}{l}>1 \text { year } \\
\text { (range) }\end{array}$ & $\begin{array}{l}p \text { Value } \\
\text { (pre-1 year) }\end{array}$ & $\begin{array}{l}p \text { Value } \\
\text { (3 months- } \\
1 \text { year) }\end{array}$ \\
\hline Mental state part UPDRS & $2(0-6)$ & $3(0-6)$ & NS & $2(0-5)$ & NS & NS \\
Mod Hoehn and Yahr in off state & $3(2.5-5)$ & $3(2-5)$ & NS & $3(2-5)$ & NS & NS \\
Mod Hoehn and Yahr in on state & $2.5(2-4)$ & $2.5(2-3)$ & NS & $2.5(2-4)$ & NS & NS \\
Time spent in on with dyskinesias & $2(1-3)$ & $1(0-3)$ & $<0.001$ & $1(1-3)$ & $<0.01$ & NS \\
Severity of dyskinesias & $3(0-4)$ & $1(0-3)$ & $<0.001$ & $1(0-2)$ & $<0.001$ & NS \\
Pain associated with dyskinesias & $2(0-4)$ & $0(0-2)$ & $<0.001$ & $0(0-3)$ & $<0.005$ & NS \\
Dystonia & $1(0-1)$ & $1(0-1)$ & NS & $1(0-1)$ & NS & NS \\
Time spent in off states & $2(1-3)$ & $1(1-4)$ & NS & $2(1-3)$ & NS & NS. \\
\hline
\end{tabular}

pre=preoperative, $\bmod =$ modified 


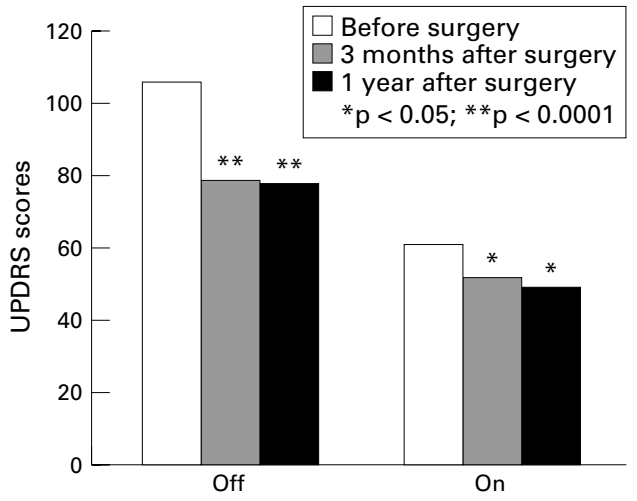

Figure 2 Mean total UPDRS scores.

with extension of the lesion into the lateral pallidum summated contralateral hemibody score for akinesia, rigidity and tremor had worsened at 1 year from 16 to 21 and in the other two it had improved minimally from 15 to 14 , and from 12 to 11 , respectively, in comparison with baseline.

UPDRS SCORES IN THE ON STATE

There was no significant change in any variable after pallidotomy in the on state, apart from a marginal improvement of speech after more than 1 year $(8 \%, p<0.05$; table 1$)$. However, in all three patients with extension of the lesion into the lateral pallidum, contralateral summated motor score had worsened minimally from 10 to $11(n=2)$ and from 3 to $4(n=1)$ relative to baseline.
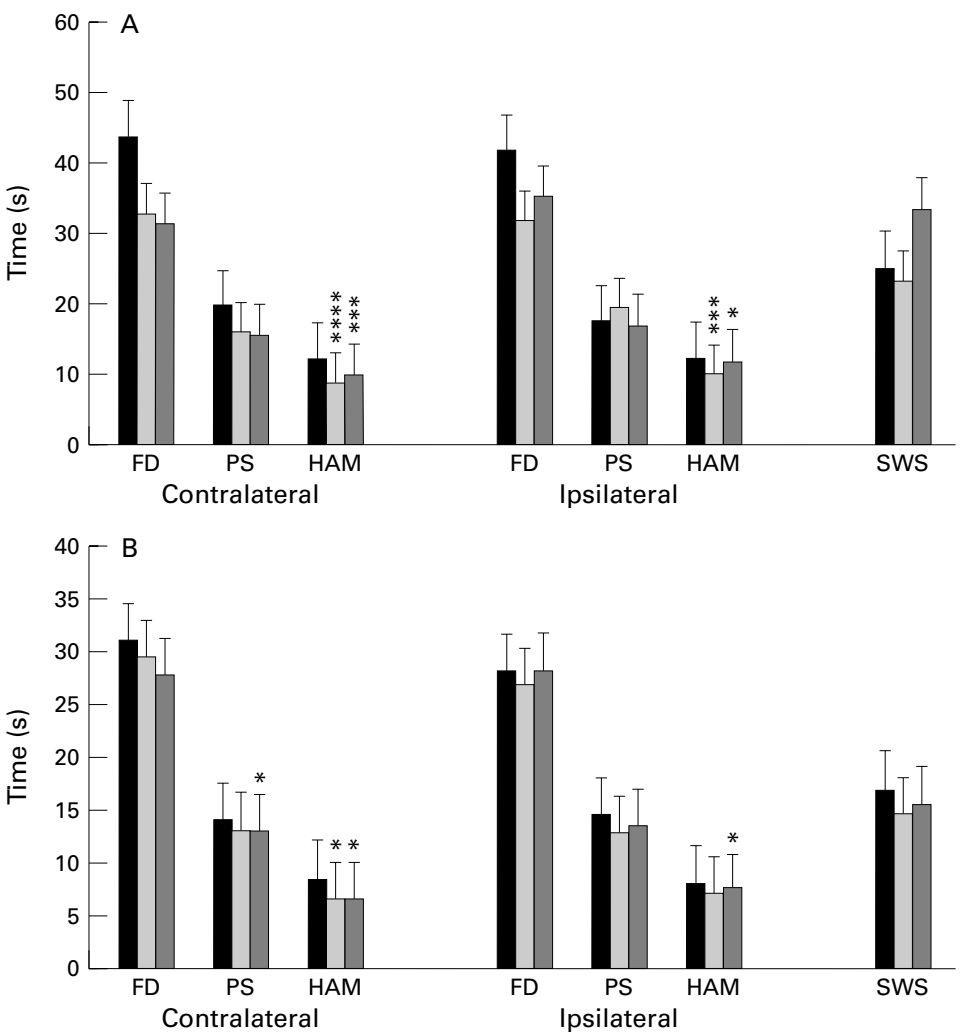

Figure 3 Median timed test results preoperatively (black bars, left), 3 months postoperatively (lighter shade, centre), and more than 1 year postoperatively (darker shade, right) for finger dexterity (FD), pronation-supination (PS), hand-arm movement (HAM) and stand-walk-sit (SWS) tests in practically defined $(A)$ off and $(B)$ best on period. ${ }^{\star} p<0.05 ;{ }^{* *} p<0.01 ;{ }^{* \star *} p<0.005 ;{ }^{\star * *} p<0.001$, in comparison with preoperative times.
OTHER UPDRS SUBSCORES

The mentation, behaviour, and mood subscore of the UPDRS and the modified Hoehn and Yahr stage in on or in off states did not change significantly 3 months and more than 1 year after pallidotomy. The time spent off, rated on the UPDRS, was also unchanged. However, the time spent on with dyskinesias decreased from an average score of $2(26 \%-50 \%$ in on states) to $1(1 \%-25 \%)$ at both assessment times $(\mathrm{p}<0.001$ and $\mathrm{p}<0.01$, respectively). Dyskinesia severity improved from an average score of 3 (severely disabling) to 1 (mildly disabling) at both time points (both $\mathrm{p}<0.001$ ). Pain associated with dyskinesias decreased from a score of 3 (severe) to 1 (slight; $\mathrm{p}<0.001$ and $\mathrm{p}<0.005$, respectively). The presence of dystonia $(0=$ no, $1=$ yes) did not change (table 2$)$. The overall improvement of total UPDRS scores in the off state was similar after 3 months and after more than 1 year $(p<0.0001$ compared with baseline at both assessments) and not different between the 3 month and the follow up assessment. The improvement of total UPDRS scores in the on state was marginally significant $(\mathrm{p}<0.05)$ at both assessment points (fig 2).

TIMED TESTS IN THE OFF STATE

There was a significant improvement in the timed hand-arm movements contralateral to the side of pallidotomy after 3 months (median improvement $18 \%, \mathrm{p}<0.001)$ as well as after more than 1 year $(20 \%, \mathrm{p}<0.005)$. Ipsilateral hand-arm movements were improved by $22 \%$ and $25 \%$, respectively $(\mathrm{p}<0.005$ and $\mathrm{p}<0.05)$. Finger dexterity, pronation-supination, and stand-walk-sit times did not change significantly (fig $3 \mathrm{~A}$ ).

TIMED TESTS IN THE ON STATE

Contralateral hand-arm movements had marginally improved at 3 months and follow up by $15 \%$ and $12 \%$, respectively (both $\mathrm{p}<0.05$ ), and pronation-supination time was marginally reduced by $14 \%$ at long term follow up $(\mathrm{p}<0.05)$. Ipsilaterally, there was a marginal improvement of hand-arm movements after longer than 1 year $(p<0.05)$ Ipsilateral pronationsupination, contralateral and ipsilateral finger dexterity times, and walking time did not change significantly (fig $3 \mathrm{~B}$ ).

MEDICATION

The mean daily total levodopa-DDCI equivalent dose was increased by $13.6 \%$ at 3 months and by $18.3 \%$ more than 1 year postoperatively $(n=17$, NS). Seven patients had increased their dose and only three had decreased it. Two patients had increased and one patient had decreased their dose of apomorphine, and were therefore not included in this medication analysis.

ADVERSE EVENTS

As reported previously, two of the original 26 patients had fatal complications. Two further patients were not assessed after more than 1 year: one had died 6 months after the operation due to an incidental glioma, and another 
Table 3 Persistent improvements in long term (1 year follow up) reports of pallidotomy

\begin{tabular}{|c|c|c|c|c|c|c|c|c|c|c|c|}
\hline \multirow[b]{2}{*}{ Author (year) } & \multirow{2}{*}{$\begin{array}{l}\text { Maximal } \\
\text { follow up } \\
\text { (months) } / n\end{array}$} & \multicolumn{2}{|l|}{ Dyskinesia } & \multicolumn{2}{|c|}{$\begin{array}{l}\text { UPDRS score } \\
\text { in off }\end{array}$} & \multicolumn{2}{|l|}{ Bradykinesia } & \multirow[b]{2}{*}{ Tremor } & \multirow{2}{*}{$\begin{array}{l}\text { Time } \\
\text { in off }\end{array}$} & \multirow{2}{*}{$\begin{array}{l}\text { Gait/stability } \\
\text { in off }\end{array}$} & \multirow{2}{*}{$\begin{array}{l}\text { On period features } \\
\text { other than dyskinesia }\end{array}$} \\
\hline & & Contralateral & Ipsilateral & part & $A D L$ & Contralateral & Ipsilateral & & & & \\
\hline $\begin{array}{l}\text { This series } \\
\text { (1998) }\end{array}$ & $14 / 20$ & + & $(+)$ & + & + & $(+)$ & - & + & - & + & - \\
\hline \multirow{2}{*}{$\begin{array}{l}\text { Dogali et al; } \\
\text { Fazzini et al } \\
(1995,1997)^{16}\end{array}$} & $\begin{array}{l}12 / 18 \\
24 / 11\end{array}$ & + & $?$ & + & + & + & + & $(+)$ & $?$ & + & \multirow{3}{*}{$\begin{array}{l}\text { Motor and ADL } \\
\text { score, gait, } \\
\text { bradykinesia, mild, } \\
\text { but persistent, } \\
\text { ?>1year } \\
(+/-)\end{array}$} \\
\hline & $36 / 10,48 / 5$ & & & & & & $\begin{array}{l}(+/-) \text { at } 4 \\
\text { years }\end{array}$ & $?>1$ year & & $?>1$ year & \\
\hline $\begin{array}{l}\text { Baron et al } \\
(1996)^{17}\end{array}$ & $12 / 15$ & + & $?$ & + & $(+)$ & + & & + & + & $(+/-)$ & \\
\hline $\begin{array}{l}\text { Kishore et al } \\
(1997)^{16}\end{array}$ & $12 / 11$ & $(+)$ & $(+)$ & + & + & $\begin{array}{l}+ \\
(6 \text { months })\end{array}$ & $\begin{array}{l}(+/-) \\
(6 \text { months })\end{array}$ & $\begin{array}{l}+ \\
\text { (6 months) }\end{array}$ & $?$ & $\begin{array}{l}+ \\
(6 \text { months })\end{array}$ & - \\
\hline $\begin{array}{l}\text { Lang et al; } \\
\text { Kumar et al } \\
(1997,1998)^{812}\end{array}$ & $\begin{array}{l}12 / 27 \\
24 / 11\end{array}$ & + & $\begin{array}{l}(+/-) \\
\text { (after } \\
1 \text { year) }\end{array}$ & + & + & + & $\begin{array}{l}(+/-) \\
\text { (after } 3 \\
\text { months) }\end{array}$ & $\begin{array}{l}(+/-) \\
(\text { small n) }\end{array}$ & $?$ & $\begin{array}{l}(+/-) \\
\text { (after 3-6 } \\
\text { months) }\end{array}$ & $\begin{array}{l}(+/-) \\
\text { (after } 1 \text { year) }\end{array}$ \\
\hline $\begin{array}{l}\text { Johansson et al } \\
(1997)^{7}\end{array}$ & $12 / ?$ & + & + & - & - & - & - & + & - & - & - \\
\hline
\end{tabular}

$\mathrm{n}=$ Number of patients; improvement rated as $+=$ persistent; $(+)=$ persistent, but decreasing; $(+/-)=$ lost or decreased; $-=$ not improved; ?=not reported; bold=consistently improved in most reports

patient could not be evaluated due to paranoid psychosis, which started 12 months after the surgical procedure in association with an increase in levodopa dose.

Four patients $(15 \%)$ had had early "major" complications that were either life threatening or interfered with their daily routine, including the first patient with MRI evidence of extension of the lesion into the internal capsule, who had developed contralateral facial weakness, motor hemineglect, and severe dysphagia and dyarthria. One patient had developed focal seizures and impairment of consciousness due to a small deep haemorrhage at the site of the lesion and a small superfical mesial frontal haematoma with infarction of the mesial frontal cortex. A third patient developed transient facial weakness and dysphagia and postural instability and one patient developed tranisent confusion and dysphagia due to a small haemorrhage at the lesion site. A further 10 had had "minor" complications. Including major and minor complications, there were persistent adverse events for more than 1 year in nine out of the $22(41 \%)$ patients assessed after this time. Three patients had asymptomatic quadrantanopia, five dysarthria, one abulia, and one had paroxysmal shaking of one limb. Ten patients had had no adverse events initially, apart from hypersalivation in one, and 13 $(59 \%)$ of the 22 patients evaluated after more than 1 year had no residual adverse phenomena.

OVERALL CLINICAL OUTCOME

All but one of the 22 patients evaluated after more than 1 year considered themselves improved overall compared with their preoperative state. In three patients the remaining ipsilateral dyskinesias are still disabling. In the remaining patient, on state contralateral and ipsilateral dyskinesias as well as contralateral motor score in off were improved at both 3 months and 21 months, but on state motor score had deteriorated after 1 year.

\section{Discussion}

The results of this follow up study suggest that the dramatic reduction of on state contralateral dyskinesias as well as the less pronounced improvement in off state activities of daily living scores after unilateral pallidotomy persist for at least 1 year. The benefit for contralateral motor scores and ipsilateral and axial dyskinesias was also maintained without significant deterioration after the first few months, albeit the improvement was less significant compared with baseline. The daily time spent with dyskinesias was significantly reduced after pallidotomy, and remained decreased throughout the follow up period. The severity of dyskinesias, as well as pain associated with dyskinesias, also remained improved postoperatively. By contrast, we did not detect a significant, persistent effect on time spent off, and there was only significant improvement of timed test scores (assessing dexterity) in one task, reflecting the only modest improvment of underlying parkinsonism. Apart from a slight improvement of ipsilateral rigidity, on state and ipsilateral off state motor scores did not improve significantly at any time in this series. Gait in off states improved marginally, whereas speech during off states had markedly worsened after 1 year.

In those of the few other reports of patients assessed at least 1 year after pallidotomy, the improvement of on state dyskinesias and of off state contralateral motor scores generally also persisted, albeit sometimes with decreased levels of significance. By contrast, initial improvement of other features was often lost during the first year (table 3).

Lang et al and Kumar et al reported 24 and 27 patients, respectively, who were evaluated 1 year, and 11 patients who were evaluated 2 years after unilateral pallidotomy. ${ }^{8}{ }^{12}$ At 1 and at 2 years postsurgery, the reduction of contralateral dyskinesias and improvement of the total UPDRS score in practically defined off that was seen was sustained. However, the reduction of ipsilateral dyskinesias and the mild improvement of on state UPDRS score (19\%) was lost after 1 year, and improvement of postural stability and gait only lasted for 3-6 months. In the study by Shannon et al, 26 patients underwent pallidotomy and 21 were 
assessed at 1 and at 6 months postoperatively. The severity and duration of dyskinesias and the motor score contralateral to the lesion were significantly diminished at 6 months, but slightly less than at 1 month. Other measures, including ipsilateral motor score, ADL, modified Hoehn and Yahr stage, time in off, and improvement of gait, had improved after 1 month, but this did not persist at 6 months postoperatively. ${ }^{9}$ Kishore et al followed up 11 out of 23 patients after pallidotomy for 1 year. The improvement of the total motor and ADL subscores of the UPDRS in off was stable up to 1 year, but ipsilateral improvement of tremor and bradykinesia in off states was not maintained after 6 months. On state total dyskinesia score improved significantly after surgery, but this improvement diminished after 1 year. ${ }^{16}$ In a report of 15 patients followed up at 1 year after pallidotomy by Baron et al, contralateral on state dyskinesias and off state tremor remained improved at 1 year. Off state motor score also improved significantly at 3 months, and this effect was maintained after the first year, but the improvement in the activity of daily living score was considerably diminished at 1 year. Both subscores in on, and several subjective measures such as speech, swallowing, and pain, were marginally improved at 3 months, but had also returned to baseline at the 1 year assessment. However, Schwab and England scores in on and off remained improved from a mean of $49 \%$ at baseline to $69 \%$ at 1 year. ${ }^{17}$ Johansson et al reported persistent improvement of dyskinesias and tremor contralateral to the surgical lesion, but there was no change of UPDRS motor scores and gait at any time. ${ }^{7}$ On the other hand, Dogali et $a l^{6}$ found that the dramatic improvement of ADL and motor subscores of the UPDRS as well as the improvement of timed tests in off and on was maintained at 1 year after ventral pallidotomy, and contralateral dyskinesias did not recur in 18 patients. By contrast, no such improvement was seen in a group of non-surgically treated patients. In the longest follow up to date, the same group later reported the results of 11 patients evaluated $2(n=1), 3(n=5)$, and 4 $(n=5)$ years after unilateral pallidotomy. In all patients benefit was maintained at the latest follow up for the motor and ADL subscores of the UPDRS, the timed tests, and dyskinesias, whereas ipsilateral improvement in timed test scores decreased after 4 years, but still remained significantly improved compared with preoperative values. ${ }^{1}$

Therefore, in all series, the most dramatic, persistent benefit of pallidotomy is the improvement of contralateral dyskinesias and, less markedly, contralateral parkinsonism in off states, both effects being maintained for at least 6 months. The amelioration of ipsilateral and axial dyskinesias in on, and of ipsilateral and axial parkinsonian features in off, if seen, is variable and often not persistent for more than a few months. On state parkinsonism did not improve to a significant degree at any time in most series. However, in most studies, including the present one, there was no deterioration of ipsilateral parkinsonism, as might have perhaps been expected due to the natural progression of the disease, and ipsilateral dyskinesias remained significantly improved after more than 1 year, albeit by less than after 3 months.

Initial, but transient, dramatic improvement of all features of parkinsonism, as sometimes seen, ${ }^{10}$ may be explained by the large placebo effect typically seen in treatment trials of Parkinson's disease, particularly as none of the currently published data were placebo controlled. Some of the initial improvement during the first month, as well as some of the adverse events during this time, could also be explained by perilesional oedema at the site of pallidotomy. However, the persistence of improvements for up to 1 year is unlikely to be due to a placebo effect and cannot be explained by perilesional oedema and so is likely to be due to the structural lesion made during pallidotomy.

The alleviation of both dyskinesias and bradykinesia by pallidotomy poses a paradox in the current model of basal ganglia function. ${ }^{18}$ By interrupting the increased inhibitory output from the medial pallidum to the thalamus, pallidotomy would be expected to alleviate bradykinesia, but also to worsen dyskinesias rather than improve them. Recently, however, Krack et al ${ }^{19}$ have shown that stimulation of the ventral part of the internal pallidum improved dyskinesias and rigidity but at the same time induced severe akinesia. Stimulation of the dorsal part, on the other hand, led to moderate improvement of akinesia, but could induce dyskinesias. Stimulation of the intermediate part of the internal pallidum achieved a good compromise mimicking the effect of pallidotomy. ${ }^{19}$ These somatotopic differences in the function of the internal pallidum may explain the paradox of pallidotomy, and also the differences in results of different centres and between individual patients. It is noteworthy that the results in our three patients in whom the lesion extended into the lateral pallidum were less favourable than in the remainder, in whom it was restricted to medial pallidum.

In this series, and in others ${ }^{9}{ }^{16}$ the morbidity and mortality of the procedure was appreciable despite the experience of these centres in stereotactic procedures. Two patients in this series had a fatal complication, and four patients had major complications after pallidotomy. Other centres have also reported fatal complications and major significant adverse events, ${ }^{920}$ illustrating the potential risk of the procedure. It is not yet clear whether the use of microelectrode recording has a significant influence on the risk of cerebral haemorrhage, the underlying complication in four fatalities. ${ }^{91016}$ There was, however, a learning curve, with 12 out of our first 14 patients experiencing adverse events, but only four out of the next 12 patients, which is similar to the experience in other centres. ${ }^{17}{ }^{21}$ Three of four patients with major complications retained persistent deficits, but because of the beneficial effects of surgery all considered themselves improved overall after more than 1 year. Most minor adverse events had improved 
or resolved after 1 year, and the most frequent persistent adverse event was dysarthria, followed by asymptomatic quadrantanopia.

\section{Conclusion}

In this study the initial, dramatic improvement in on state contralateral dyskinesias, and the more modest improvement in off state parkinsonism after unilateral pallidotomy persisted for more than 1 year. A persisting reduction in ipsilateral and axial dyskinesias and contralateral motor scores was also seen, albeit diminished after 1 year. On state parkinsonism and ipsilateral off state parkinsonism in this series did not improve significantly at any time point. However, in view of the potential risks associated with this invasive procedure, careful selection of patients is necessary. Young patients who have severe, asymmetric, on state dyskinesias are most likely to benefit from pallidotomy. If carefully chosen, severely disabled patients with levodopa induced dyskinesias and severe off state parkinsonism can be improved dramatically and persistently by this procedure. By contrast, patients with predominantly axial features such as impairment of gait, balance, and speech are less likely to improve. Whether the use of microelectrode recordings adds to the high rate of complications or is necessary for good outcome still needs to be determined.

AS was supported by a grant from SmithKline Beecham Pharmaceuticals, UK, MS was funded by the Medical Research Council, London, UK and MDT was supported by a Harvard University Warren Whitman Richardson Fellowship.

1 Fazzini E, Dogali M, Sterio D, et al. Stereotactic pallidotomy for Parkinson's disease: a long-term follow-up of unilateral for Parkinson's disease: a long-term foll
pallidotomy. Neurology 1997;48:1273-7.

2 Laitinen LV. Pallidotomy for Parkinson's disease. Neurosurg Clin N Am 1995;6:105-12. 3 Iacono RP, Shima F, Lonser RR, et al. The results, for patients with Parkinson's disease. Neurosurgery 1995;36: for patien

4 Lozano AM, Lang AE, Galvez-Jimenez N, et al. Effect of GPi pallidotomy on motor function in Parkinson's disease. Lancet 1995;346:1383-7.

5 Sutton JP, Couldwell W, Lew MF, et al. Ventroposterior medial pallidotomy in patients with advanced Parkinson's disease. Neurosurgery 1995;36:1112-6

6 Dogali M, Fazzini E, Kolodny E, et al. Stereotactic ventral pallidotomy for Parkinson's disease. Neurology 1995;45: 753-61.

7 Johansson F, Malm J, Nordh E, et al. Usefulness of pallidotomy in advanced Parkinson's disease. $\mathcal{F}$ Neurol Neurosurg Psychiatry 1997;62:125-32.

8 Lang AE, Lozano AM, Montgomery E, et al. Posteroventral medial pallidotomy in advanced Parkinson's disease. $N$ Engl f Med 1997;337:1036-42.

9 Shannon KM, Penn RD, Kroin JS, et al. Stereotactic pallidotomy for the treatment of Parkinson's disease. Efficacy and adverse effects at 6 months in 26 patients. Neurology 1998;50:434-8.

10 Samuel M, Caputo E, Brooks DJ, et al. A study of medial pallidotomy for Parkinson's disease: clinical outcome, MRI location and complications. Brain 1998;121:59-75.

11 Ondo WG, Jankovic J, Lai EC, et al. Assessment of motor function after stereotactic pallidotomy. Neurology 1998;50: 266-70.

12 Kumar R, Lozano AM, Montgomery E, et al. Pallidotomy and deep brain stimulation of the pallidum and subthaamic nucleus in advanced Parkinson's disease. Mov Disord 1998;13(suppl 1):73-82.

13 Gibb WR, Lees AJ. The relevance of the Lewy body to the pathogenesis of idiopathic Parkinson's disease. $f$ Neurol Neurosurg Psychiatry 1988;51:745-52.

14 Langston JW, Widner H, Goetz CG, et al. Core assessment program for intracerebral transplantations (CAPIT). Mov program for intrace

15 Goetz CG, Stebbins GT, Shale HM, et al. Utility of an objective dyskinesia rating scale for Parkinson's disease: inter- and intrarater reliability assessment. Mov Disord 1994;9:390-4.

16 Kishore A, Turnbull IM, Snow BJ, et al. Efficacy, stability and predictors of outcome of pallidotomy for Parkinson's disease. Six-month follow-up with additional 1-year observations. Brain 1997;120:729-37.

17 Baron MS, Vitek JL, Bakay RA, et al. Treatment of advanced Parkinson's disease by posterior GPi pallidotomy: 1-year results of a pilot study. Ann Neurol 1996;40:355-66.

18 Marsden CD, Obeso JA. The functions of the basal ganglia and the paradox of stereotaxic surgery in Parkinson's disease. Brain 1994;117:877-97.

19 Krack P, Pollak P, Limousin P, et al. Opposite motor effects of pallidal stimulation in Parkinson's disease. Ann Neurol 1998;43:180-92.

20 Obeso JA, Guridi J, Obeso JA, et al. Surgery for Parkinson's disease. $\mathcal{F}$ Neurol Neurosurg Psychiatry 1997;62:2-8.

21 Golbe LI. Pallidotomy for Parkinson's disease: hitting the target? Lancet 1998;351:998-99. 